\title{
ANALISIS MAKNA UNSUR NARATIF PADA VIDEO KLIP BTS “ON”
}

\author{
${ }^{1}$ Lasma Uli Situmorang, ${ }^{2}$ Muhammad Ali Mursid Alfathoni \\ Prodi Film dan Televisi \\ Fakultas Seni dan Desain Universitas Potensi Utama \\ mhd.ali8mursid@gmail.comr),ulasma74@gmail.com²)
}

\begin{abstract}
ABSTRAK
Penelitian ini bertujuan untuk mengetahui makna yang terdapat dalam unsur naratif pada video klip BTS "On". Boyband di Korea Selatan pada masa kini mengharuskan setiap agency yang menaunginya untuk berpikir kreatif agar mampu mempopulerkan trainee yang debut menjadi idola penikmat K-pop. Kepopuleran BTS tidak terlepas dari konsep video clips yang sarat akan makna. Adanya persaingan ketat antar Makna tersebut tercermin dalam elemen struktur unsur naratif yang disusun layaknya cerita dengan maksud tersembunyi dibaliknya seperti yang terdapat dalam video klip lagu "On". Penelitian ini menggunakan metode pendekatan secara deskriptif kualitatif. Dengan menggunakan metode tersebut akan dilakukan proses mendeskripsikan makna yang ada dibalik unsur naratif pada video klip lagu "On". Dalam penelitian ini juga menggunakan teori naratif David Bordwell dan Himawan Pratista yang mencangkup alur/plot, karakter, konflik, dan setting. Hasil penelitian menunjukkan bahwa dalam video klip lagu "On" terdapat makna yang tersembunyi dibalik unsur naratif yang meliputi urutan waktu plot pola linear, konflik, karakter penokohan, dan sebagainya. Video klip lagu "On" yang diproduksi dengan konsep cinematic video tentu elemen naratif tersebut saling berkaitan dalam ruang dan waktu tertentu.
\end{abstract}

Kata kunci: Analisis Makna, Unsur Naratif, Video Klip BTS “On”.

\section{ABSTRACT}

This study aims to find out the meaning contained in the narrative element in the BTS video clip "On". Boybands in South Korea today require every agency that houses it to think creatively in order to be able to popularize trainees who debuted to become K-pop idols. Bts's popularity is inseparable from the concept of video clips that are full of meaning. The existence of intense competition between meanings is reflected in the narrative element structure elements that are arranged like a story with the hidden intent behind it as contained in the video clip of the song "On". This study uses qualitative descriptive approach methods. By using this method, the process will be done to describe the meaning behind the narrative element in the video clip of the song "On". In this study also used the narrative theory of David Bordwell and Himawan Pratista covering plots, characters, conflicts, and settings. The results showed that in the video clip of the song "On" there is a hidden meaning behind the narrative element that includes the time sequence of linear pattern plot, conflict, character affirmation, and so on. Video clip of the song "On" produced with the concept of cinematic video of course the narrative elements are interconnected in a certain space and time.

Keywords: Meaning Analysis, Narrative Element, Video Clip BTS On.

\section{PENDAHULUAN}

K-Pop merupakan jenis musik yang sangat populer yang berasal dari negara Korea Selatan. Musik aliran K-Pop sampai saat ini mengalami perkembangan yang sangat pesat dan diminati oleh orang-orang dari berbagai belahan dunia. K-Pop sendiri merupakan 
bagian yang tidak terpisahkan dari Korean Wave yang sudah menyebar diberbagai negara di dunia. Ditengah demam K-pop yang marak di dunia, banyak sekali boyband baru yang bermunculan di Korea. Persaingan ketat dengan banyaknya boyband yang ada, mengharuskan agency Big Hit Entertaiment menuangkan konsep video klip yang menarik perhatian kaum Korean Wave. Korean Wave merupakan istilah dari penyebaran budaya pop Korea secara global di berbagai negara. Menurut Frulyndese K. Simbar (2016) menyatakan bahwa, Korea Selatan dalam dekade ini mampu menyebarkan produk budaya populer yang mereka miliki ke dunia internasional. Produk budaya tersebut mulai dari drama film, lagu, fashion, gaya hidup, bahkan produk lainnya.

Agency Big Hit Entertainment merupakan sebuah agency yang memanejemeni grup K-Pop yang fenomenal masa kini, yakni BTS serta perilaku penggemarnya (Diari dan Mahyuni, 2019). Adapun salah satu konsep yang disematkan Big Hit Entertaimen pada BTS (Bangtan Sonyeondan) boyband asuhannya tersebut dengan membuat cerita naratif dalam video klip lagu-lagunya. Adapun bentuk penerapan cerita naratif terhadap lagu BTS seperti pada video klip lagu "On”. Dalam video klip lagu "On" terdapat rangkaian peristiwa yang berhubungan satu sama lain dan terikat oleh logika sebab akibat (kausalitas) yang terjadi dalam suatu ruang dan waktu. Adanya rangkaian logika sebab akibat yang terdapat pada video klip lagu "On" tentu dapat memunculkan makna naratif disetiap unsur visual yang ada dalam video klip lagu "On". Menurut Murwonugroho dan Piliang (2015) bahwa video klip dapat berfungsi sebagai bentuk penyampaian pesan atau makna yang dipresentasikan secara visual melalui metafora-metafora yang menjadi jembatan antara imajinasi dan realitas yang ada di kehidupan nyata.

Sebagai salah satu produk multimedia yang sangat diminati dan sering dijumpai baik di internet maupun televisi, video klip diproduksi pada saat sekarang ini cenderung menggunakan konsep cinematic video seperti yang dilakukan oleh agency Big Hit Entertainment. Pembuatan video klip dengan konsep cinematic video merupakan sebuah jenis pembuatan video klip dengan memfokuskan terhadap narasi serta jalan cerita dalam menghasilkan visual yang mudah dan dapat dimengerti oleh penonton. Tanpa disadari visual yang ditampilkan dalam video klip mampu mengkontruksikan sebuah trend, kebenaran, bahkan ideologi (Hermansyah, 2019).

Seorang profesor dari Sejong University, Lee Ji Young menulis buku tentang keberhasilan BTS dan kesuksesannya di industri musik dunia. Di kutip dari situs www.koreaboo.com, sang profesor mengatakan bahwa lagu-lagu BTS yang mengikuti tren dan memiliki pesan serta makna mendalam di balik setiap lagu mereka. Dilansir dari media online koreaboo, BTS juga telah menerima medali di bidang kebudayaan Hwagwan Order of Cultural Merit yang hanya diterima oleh beberapa orang saja dalam 50 tahun terakhir.

Unsur naratif dalam video klip lagu "On" tercermin secara visual melalui rangkaian cerita, peristiwa dan plot yang terdapat dalam video klip lagu "On". Selain itu, dalam video klip lagu "On" juga terdapat urutan waktu pola linear A-B-C-D-E. Urutan pola waktu tersebut berfungsi sebagai penggerak pelaku cerita atau tokoh utama, pendukung, permasalahan dan konflik. Konflik yang tercermin dalam unsur naratif pada video klip lagu "On" memvisualisasikan perjuangan para tokoh yang mencerminkan tujuan dan harapan. Selain itu, usnur naratif ruang dan setting lokasi para tokoh mampu membentuk struktur naratif yang epik dengan mengusungkan tema klasik yang happy anding.

Naratif adalah suatu rangkaian peristiwa yang berhubungan satu sama lain dan terkait oleh logika sebab akibat yang terjadi dalam suatu ruang dan waktu (Armanto, 2013). Tanpa adanya unsur naratif tentu sebuah cerita yang terdapat dalam video klip lagu "On" tentu tidak akan terjadi dan menimbulkan makna tertentu. Adanya unsur naratif 
dalam video klip lagu "On" tentu dapat mengambarkan hubungan antar elemen yang terdapat dalam unsur naratif yang terdapat dalam video klip lagu "On”.

Untuk mendapatkan makna yang ada dalam unsur naratif pada video klip "On" peneliti menggunakan metode pendekatan deskriptif kualitatif. metode penelitian merupakan sebuah proses yang berfungsi dalam mencari tahu sebuah informasi yang ada disebuah objek dengan cara melakukan proses pemecahan masalah dengan menggunakan sudut pandang secara teoritis maupun praktis. Menurut Bogdan dan Taylor dalam Moleong (1993) penelitian kualitatif merupakan sebuah penelitian yang bertujuan untuk menghasilkan data secara deskriptif yang dapat berupa kata-kata yang tertulis maupun secara lisan dari orang atau prilaku yang bisa diamati. Dalam hal ini, peneliti melakukan pengamatan terhadap unsur naratif yang terdapat dalam video klip lagu "On" agar dapat mendeskripsi makna yang ada dibalik unsur naratif tersebut. Untuk memperkuat hasil analisis terhadap video klip lagu "On" peneliti menggunakan teori naratif David Bordwell dan Himawan Pratista. Dalam teori tersebut unsur naratif mencangkup alur/plot, karakter, konflik, dan setting. Sebagai sebuah video klip yang diproduksi dengan konsep konsep cinematic video tentu cangkupan dari teori naratif diatas tidak bisa diabaikan.

\section{II.STUDI LITERATUR}

Adapun yang menjadi studi literatur dalam penelitian ini adalah hasil penelitian Muhammad Ivan Hermansyah yang berjudul "Makna Simbolik Dalam Musik Video Klip Kendrick Lamar "Humble" tahun 2019. Hasil penelitian ini menunjukkan bahwa dalam music video klip "Humble" terdapat pesan-pesan yang terselubung dan memiliki arti yang sangat besar dan dalam video klip juga menyinggung isu, kalangan, dan rasisme. Penelitian Novi Retnosari yang berjudul "Analisis Lagu Sebagai Penguat Unsur Naratif Pada Film Musikal "Rena Asih" tahun 2018. Hasil penelitian menunjukkan bahwa lagu sangat berfungsi sebagai unsur penguat dalam naratif dan menunjukkan kadar naratif yang terdapat pada masing-masing lagu dan memiliki pengaruh terhadap jalannya cerita yang terdapat dalam sebuah film. Selanjutnya, hasil penelitian Rayudaswati Budi dan Suci Wahyuningsih yang berjudul "Visualisasi Makna Surealisme Pada Video Klip Up And Up (Perspektif Semiotika Charles Sanders Pierce)" tahun 2018. Hasil penelitian menunjukkan bahwa tanda yang sering muncul pada video klip Up And Up seperti Api, Langit, dan Laut yang merupakan bentuk representament dari bumi, yang objeknya adalah manusia. Melalui cerita yang terdapat dalam video klip ini Coldplay mencoba untuk menyampaikan pesan kepada khalayak dengan cara menyandingkan manusia dengan fenomena alam di sekelilingnya. Adanya teknik surealisme yang digunakan menunjukkan ketidaksukaannya terhadap kondisi sosial, alam, dan politik saat ini.

\section{PEMBAHASAN}

BTS (Bangtan Sonyeondan) adalah boyband dibawah naungan agency Big Hit Entertaiment yang menjadi boyband Korea Selatan yang meraih banyak penghargaan musik bergengsi di Asia dan Amerika Serikat. BTS beranggotakan tujuh pria yaitu Jimin, V, RM (leader), Jungkook, J-Hope, Jin, Suga, yang di haruskan memiliki kemampuan dence yang mumpuni. Pada tanggal 21 Februari 2020, BTS merilis album berjudul MAP OF THE SOUL:7 dengan single berjudul "On". Berbagai sumber mengisahkan makna di balik video klip BTS “On”, mengaitkannya dengan perjuangan para member BTS selama tujuh tahun berkarir dalam member boyband Bulletproof Boy Scouts (dalam bahasa English).

Dalam video klip “On” BTS tidak terlepas dari unsur naratif didalamnya, opening yang memperlihatkan permasalahan dan konflik kematian manusia serta seekor merpati 
putih tertusuk anak panah yang ditemukan oleh Jin. Unsur naratif tersebut tentu memiliki memiliki tujuan yang tergambar pada video klip "On". Pada saat seluruh member BTS termasuk seekor merpati putih yang hidup kembali kemudian hendak dibebaskan dari dalam sangkar serta seluruh orang-orang yang mati dan merpati putih tersebut hidup kembali dan berjalan dibelakang dan para member BTS. Selain itu, urutan waktu yang terdapat dalam video klip lagu "On" mencerminkan pola linear yang berjalan sesuai urutan aksi dan peristiwa yang dapat mempermudah penonton maupun peneliti dalam memahami hubungan kausalitas yang terdapat pada video klip "On”. Pola linear yang menggambarkan alur plot A-B-C-D-E dengan kuatnya mencerminkan sebuah makna dalam setiap rangkaian peristiwa yang terdapat dalam video klip lagu "On".

\section{III.1 Makna Pada Urutan Waktu Pola Linear Video Klip On}

Sebuah cerita tidak mungkin terjadi tanpa adanya unsur waktu (Pratista, 2008:36). Elemen waktu yang digunakan dalam video klip BTS "On" adalah pola linear dengan mengibaratkan plot A-B-C-D-E, jika di aplikasikan pada video klip "On" maka sebagai berikut:

Plot A; Awal cerita Jin melihat banyak orang yang mati disekitarnya, pandangannya tertuju pada seekor merpati putih yang tertusuk anak panah. Adapun capture adegan tersebut terlihat seperti berikut ini:

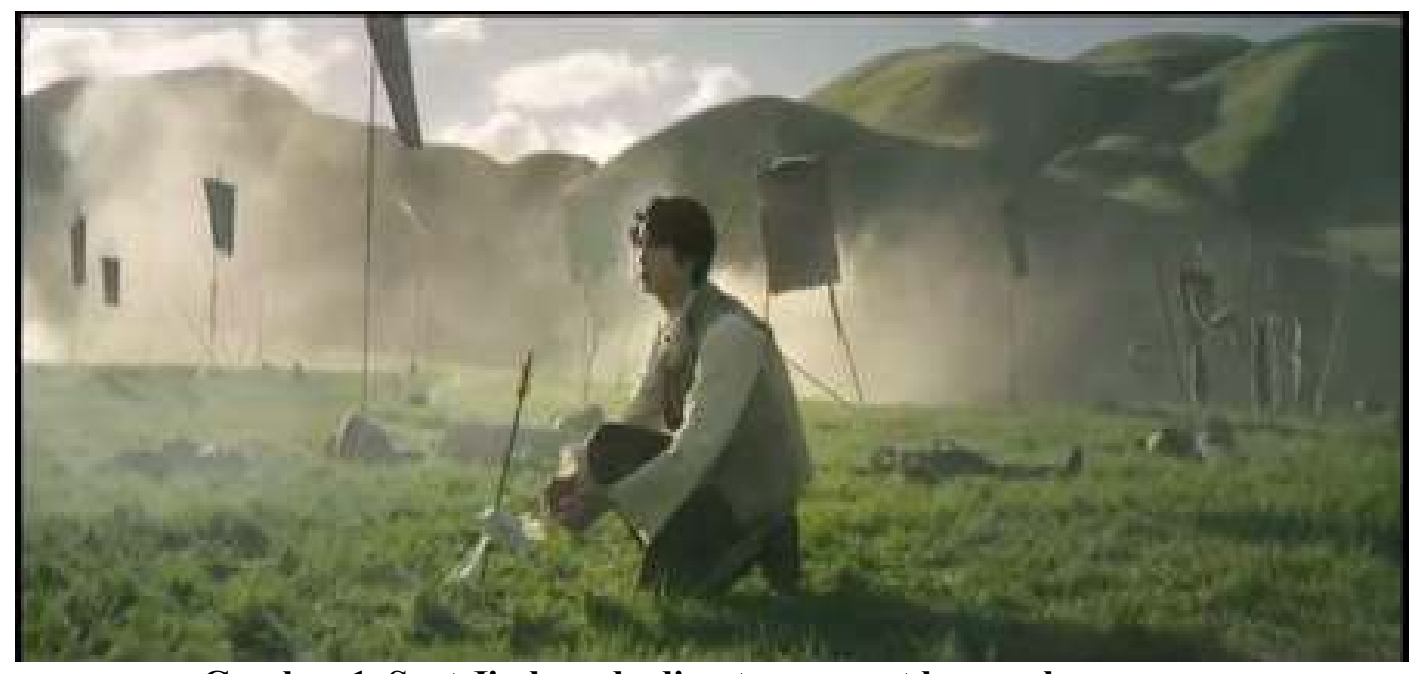

Gambar 1. Saat Jin berada di antara mayat berserakan (sumber: Capture video klip BTS “On”)

Visualisasi yang memperkenalkan awal permasalahan tentang kematian masal dimana Jin sendiri terlihat bertanya-tanya mengapa keadaan tragis itu terjadi. Pada adegan klip selanjutnya saat Jin memegang merpati putih yang telah mati tertusuk panah itu, Jin menatap ke langit dengan ekspresi yang menyiratkan makna seolah bertanya pada sang pencipta; "mengapa semua tragedi ini terjadi?"

Plot B; Jungkook berlari dan kedua tangannya terikat kawat duri seperti tahanan yang kabur dari penjara labirin, Jungkook melihat sekali ke langit lalu sekali menoleh ketembok labirin tersebut sembari terus berlari di padang luas menjauh dari labirin.

Plot $\mathrm{C}$; $\mathrm{V}$ yang berbaring di atas tanah menghadap ke langit, kepalanya yang bertumpu pada potongan kayu, menekukkan kaki kirinya, merentangkan kedua tangan seperti adegan penyaliban Isa Almasih pada ajaran umat Nasrani. Serta seorang gadis kecil yang duduk di samping $\mathrm{V}$ dengan mata ditutup ikatan tali kain.

Plot D; RM yang berdiri diantara binatang, dengan sebuah kapal karam seperti pada 
kisah bahtera Nuh yang perintahkan untuk menyelamatkan serta binatang dari air bah. Di akhir bagian ini, RM juga terlihat sejenak posisi tangan kanan menyentuh dadanya sambil menatap ke langit.

Plot E; Jimin yang berdiri diantara tumpukan drum yang terbuang, dan seorang anak yang duduk diam di atas mobil rongsokkan memegang drum. Pada bagian ini Jimin mengangkat tangan kanannya menunjuk dan menatap ke langit, seperti gambar berikut ini:

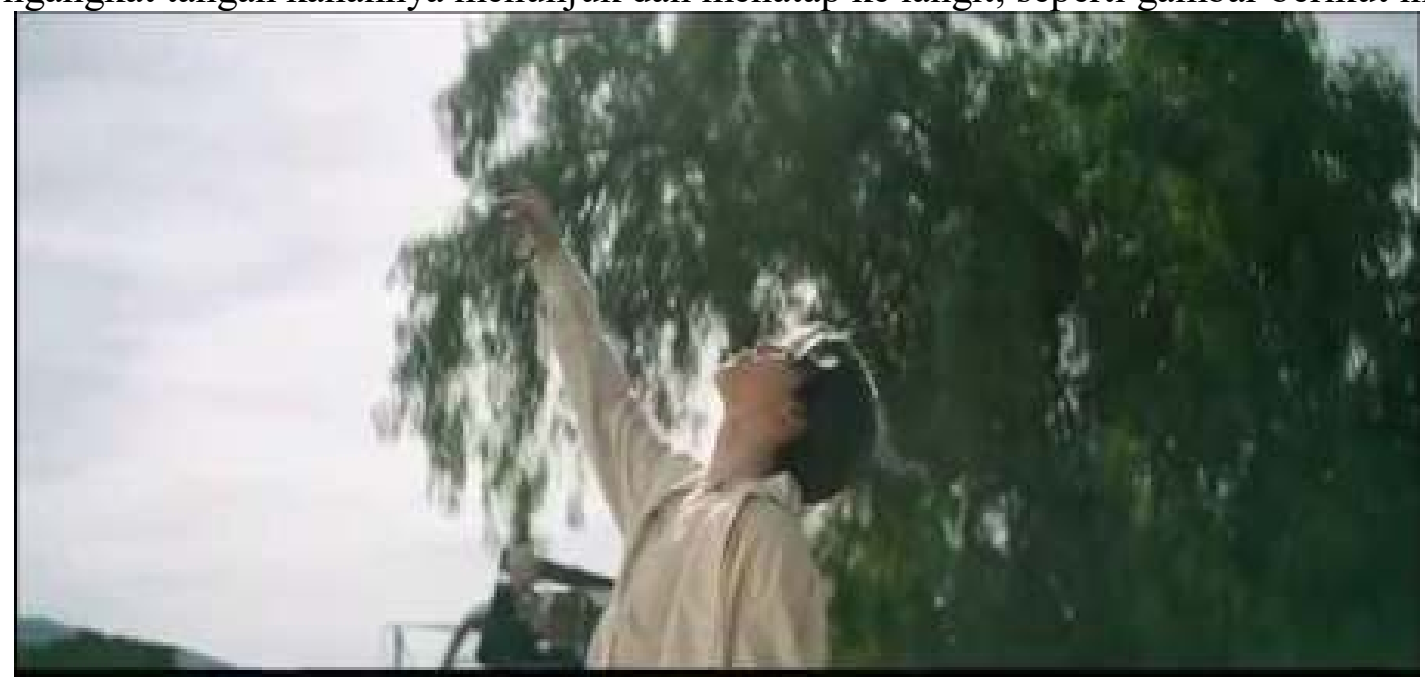

Gambar 2. Saat Jimin berada di antara rongsokan drum, dan menatap ke langit (sumber: Capture video klip BTS “On”)

Dalam setiap urutan pola plot linear pada video klip BTS "On" memiliki makna yang sama, pada plot selajutnya member BTS yaitu J-Hope yang berada di antara pepohonan Dancing Forest ada seekor burung mematuk tubuh Jungkook ketika ia pingsan. J-Hope menari dan merentangkan kedua tangannya menatap kelangit setelah burung terbang dan tubuh Jungkook menghilang, berikut gambarnya:

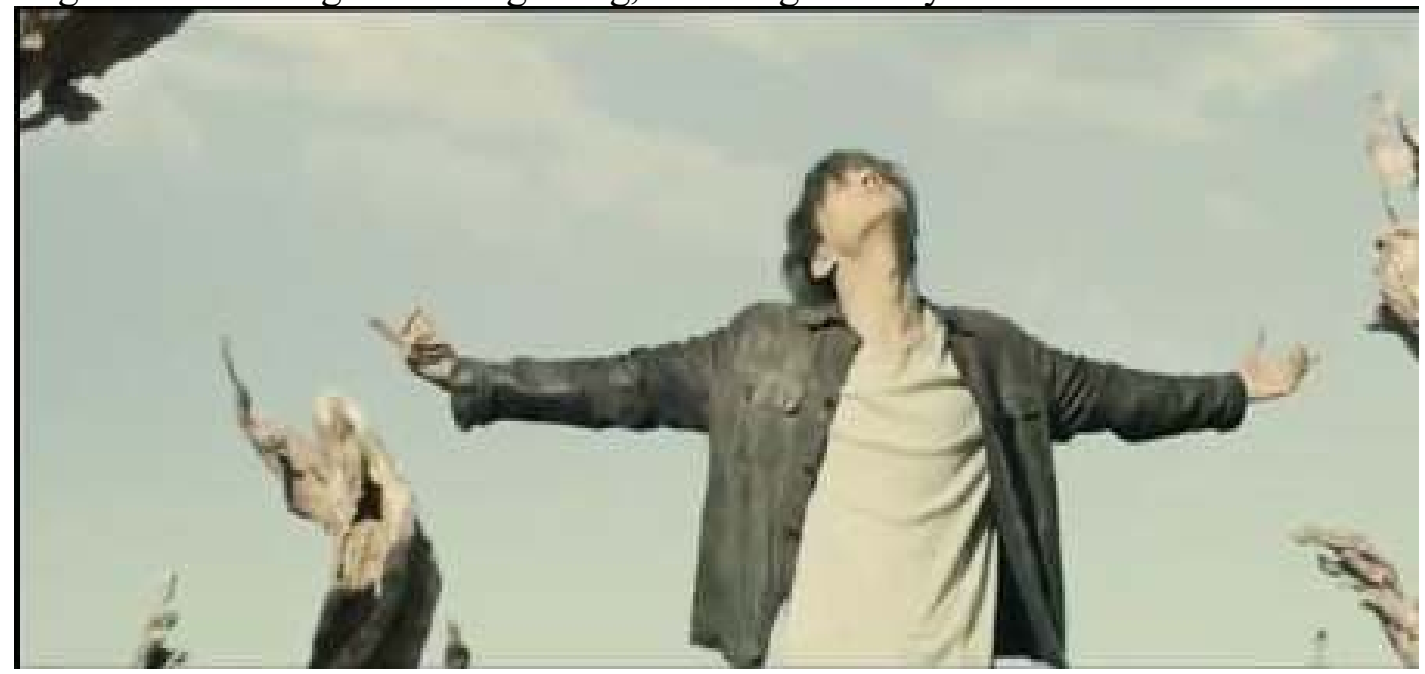

Gambar 3. Saat J-Hope berada diantara pepohonan dancing forest dan menatap ke langit

(sumber: Capture video klip BTS “On”)

Visualisasi urutan waktu pola linear bermakna bahwa setiap member BTS melihat pada sumber cahaya seperti terus berharap dan akan terus bersinar bagi para ARMY, bagi Big Hit Entertaiment yang menaungi mereka, bagi keluarga RM, J-Hope, Jungkook, Jimin, 
Suga, Jin, dan V. Bukti bahwa BTS mampu terus bersinar selama tujuh tahun, meski beberapa kali sempat diterpa kesulitan dan hendak membubarkan diri.

\section{III.2 Makna Dari Permasalahan dan Konflik Pada Video Klip "On"}

McCudden (2011:21) menyebutkan kegiatan terakhir menjadi penggemar (fans) adalah membangun pengetahuan. Pengetahuan dapat diambil dari berbagai berbagai bentuk tergantung pada jenis objek yang digemari dan preferensi individu dalam komunitas maupun sub-komunitas di dalamnya. Peneliti akan menjelaskan makna pada permasalahan dan konflik yang ada pada video klip BTS "On" berdasarkan pengetahuan peneliti yang disimpulkan dari berbagai sumber. Beberapa media online mengaitkan video klip "On” dengan beberapa adegan karya sastra modern seperti film, peneliti tidak menampik persepsi media tersebut.

Permasalahan awal yang bermula dari kematian banyak orang dan seekor merpati putih tanpa menceritakan penyebabnya, membuat penikmat K-pop penasaran dengan kelajutan tiap bagian dari video klip "On". Seekor merpati di zaman dahulu digunakan sebagai pengantar pesan. Dalam agama Nasrani merpati putih di lambangkan sebagai sosok Roh Kudus dalam kisah pembabtisan Isa Almasih yang dilakukan oleh Yohanes seorang pembabtis. Dalam pernikahan manusia, merpati putih juga dianggap melambangkan kesetiaan. Jin memasukkan merpati itu ke kandang burung, dan membawanya ke ruangan yang penuh dengan kandang kosong. Jin menutup kandang yang berisi merpati mati itu dengan kain, kandang itu bergerak dan Jin melihat ke arah sumber cahaya dari ruangan itu, yang terlihat pada gambar berikut:

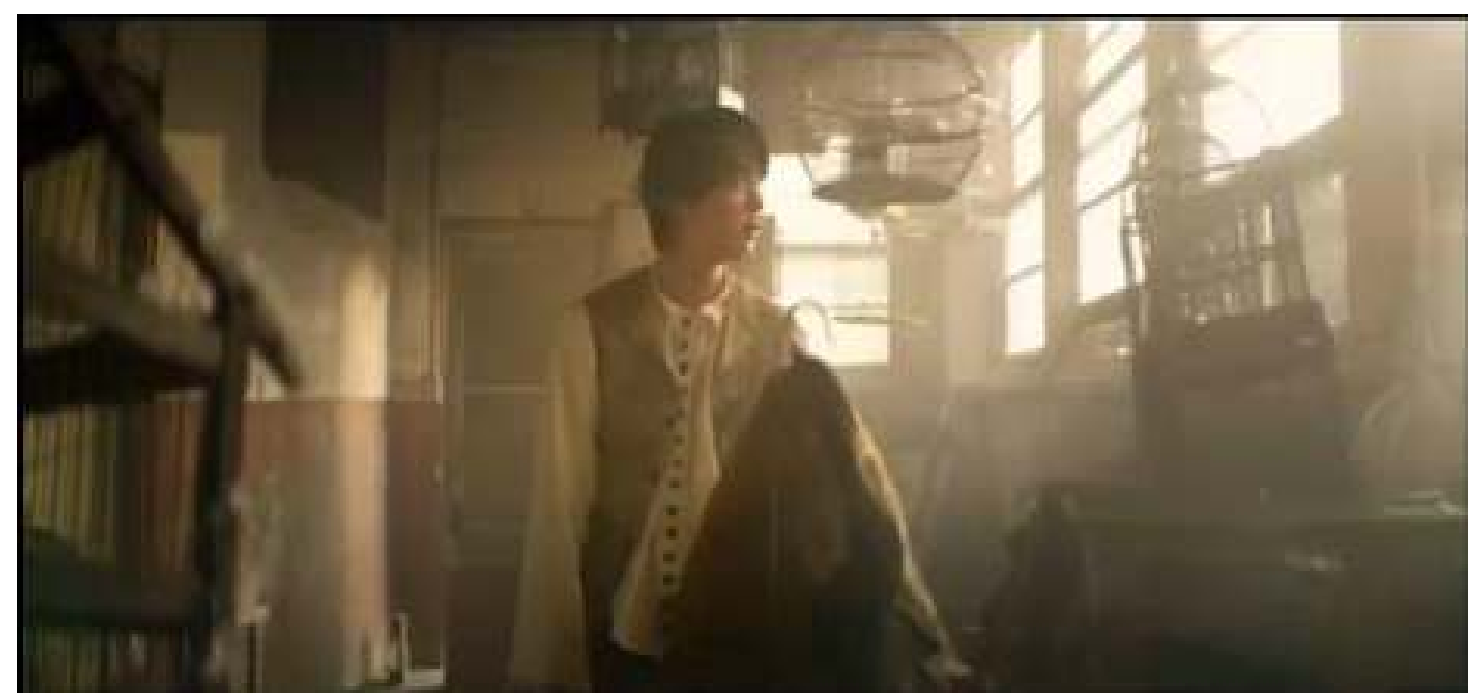

Gambar 4. Saat Jin berada di ruangan penuh

kandang burung

(sumber: Capture video klip BTS “On”)

Pada konflik ini Jin bersabar dan tidak meninggalkan merpati yang tertusuk panah itu di tempatnya semula mati, Jin percaya akan ada keajaiban terjadi baginya dan merpati putih itu. Harapan Jin terjawab ketika kandang merpati yang ditutupnya dengan kain bergerak, menurut para ARMY Jin selalu berperan sebagai pelindung pada beberapa video clips lagu BTS. Konflik yang di alami Jungkook menambah rasa penasaran para Kpop, bagaimana cara Jungkook melepaskan duri yang mengikat kedua tangannya? Pada plot B peneliti telah memaparkan bahwa Jongkook melarikan diri dari labirin yang lebih mirip tembok penjara, Jungkook terus berlari meski ia tidak tau kemana tujuannya. Ia menatap ke langit beberapa kali sebelum terjatuh pingsan di bawah rindangnya pepohonan, seperti yang terlihat pada gambar berikut: 


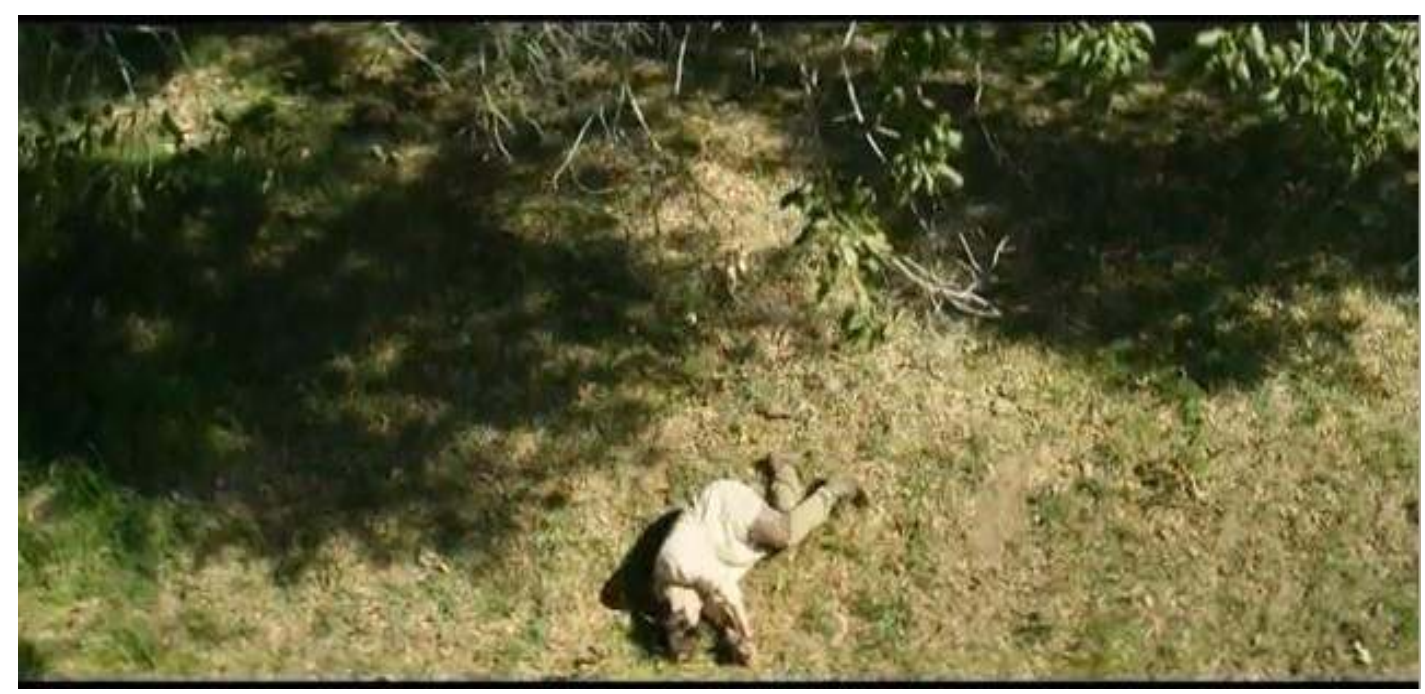

Gambar 5. Saat Jungkook pingsan dibawah rindangnya pepohonan (sumber: Capture video klip BTS “On”)

Meski Jungkok tidak tau arah dan tujuannya, ia terus berlari sembari beberapa kali menatap ke langit seolah berseru pada sang pencipta untuk memberinya arah dan tujuan yang tepat agar bisa terbebas dari belenggu duri yang mengikatnya. Dalam chanel youtube resmi Big Hit Entertaiment behine the scene video "On", Jungkook mengatakan perannya dalam MV (Music Video) tersebut sebagai sesorang yang memiliki kekuatan supranatural yang hendak di asingkan karena dianggap pengikut iblis.

\section{III.3 Makna Penokohan dan Tokoh Pada Video Klip "On”}

Dikutip dari salah satu kanal youtube "Update Hits K-Pop K-Drama (K-Hist)", BTS memang selalu dikait-kaitkan dengan teori-teori sastra dari setiap music video (MV) mereka. Karakter setiap member BTS selalu disematkan dalam setiap video klip mereka, tidak terkecuali video klip "On". Berikut peran dan makna dari masing-masing member BTS dalam video clip "On" :

1. Jin

Dalam beberapa music video, Jin sering mendapat peran dengan karakter sebagai seorang pelindung, tidak terkecuali dalam MV On. Menyelamatkan seekor merpati putih yang telah mati dan memasukan merpati tersebut ke dalam sangkar, membawanya kedalam sebuah gudang penuh sangkar kosong. Menjelang akhir $M V$ Jin seolah memiliki keajaiban untuk menghidupkan kembali sang merpati dan membebaskannya dari dalam sangkar.

2. Jimin dan $\mathrm{V}$

Adegan saat Jimin menari dengan penghayatan diantara drum yang dibuang, dan seorang anak yang hanya duduk diam dalam lamunannya sembari memegang sebuah drum. Setelah Jimin bernyanyi, anak tersebut ikut memainkan drumnya dengan bersemangat mengiringi tarian Jimin. Adegan $\mathrm{V}$ yang sedang berbaring di tanah menatap kelangit, dan seorang anak perempuan yang mengenakan penutup mata diam seolah tak tahu arah. Saat itu V membuka penutup mata anak tersebut dan menuntunnya berjalan perlahan menuju suatu tempat seperti gerbang tembok raksasa. Keduanya berperan sebagai trandsetter (panutan) bagi kaum muda (young generation) tidak hanya dalam video klip, namun juga dalam kehidupan nyata kedua member BTS Jimin dan V. 
3. J-Hope

Adegan berawal saat J-Hope hanya berdiri santai diantara pepohonan yang melengkung, di dekat tubuh Jungkook yang terkulai lemas dengan seekor burung kematian mematuk tubuh Jungkook. Ketika J-Hope mulai menggerakkan tangannya hendak menari, burung tersebut berlalu. Saat J-Hope menari dengan semangat, tubuh Jungkook yang terkulai lemas menghilang dan berlalu. J-Hope menyelamatkan Jungkook dari burung kematian tersebut, dan setelahnya J-Hope merentangkan kedua tangannya dan menatap kelangit dari arah sumber cahaya berada.

4. $\mathrm{RM}$

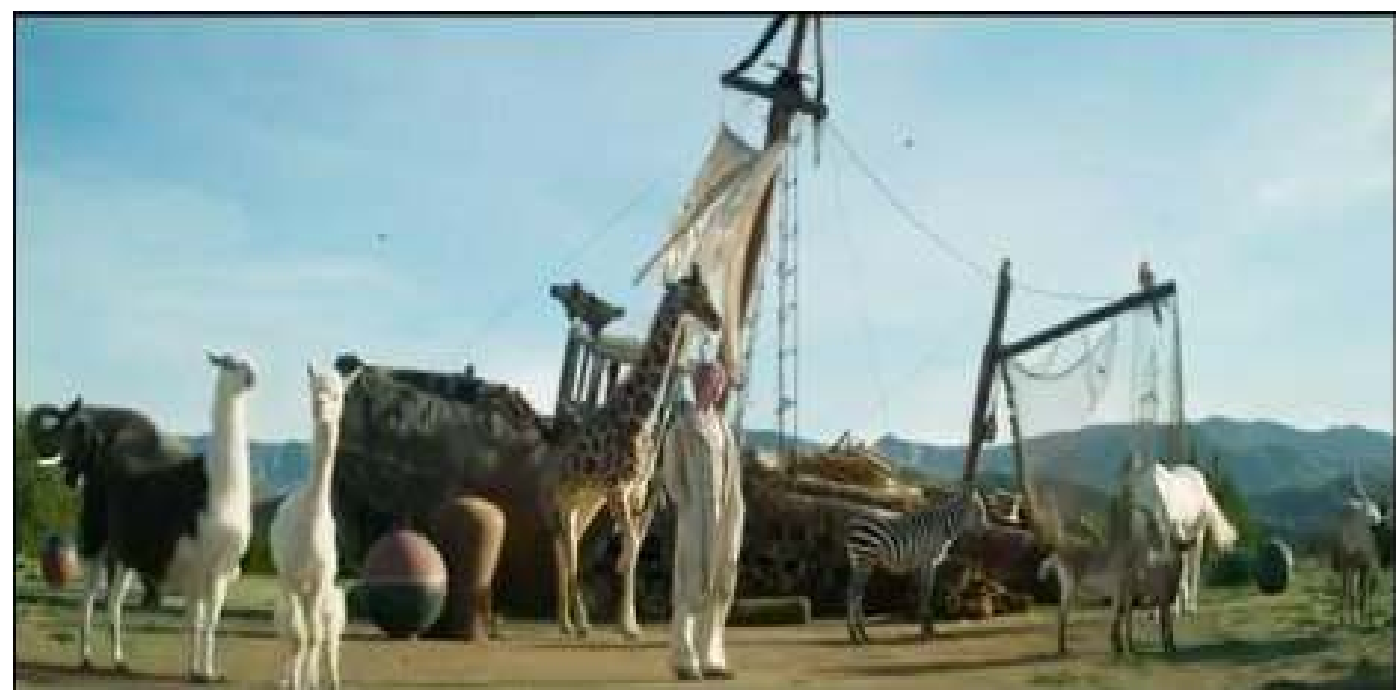

Gambar 6. Adegan saat RM berada diantara bermacam jenis hewan (sumber: Capture video klip BTS “On”)

Karakter peran RM dalam video klip BTS On terkesan spesial, berada diantara berbagai pasang jenis hewan dan berdiri dengan santai diantara mereka. IQ yang dimiliki RM diatas rata-rata para Boy Band di Korea Selatan, wawasannya seperti buku ensiklopedia yang juga berkaitan dengan karakternya dalam video klip On yang dikait-kaitkan oleh penggemar sebagai karakter nabi Nuh (Noah).

\section{Jungkook}

Adegan yang dilakoni oleh Jungkook sebagai seseorang yang menderita dengan duri ditangannya, berjuang mencari kebebasan tergambar dalam banyaknya segmen adegan Jungkook dalam MV On. 


\section{Suga}

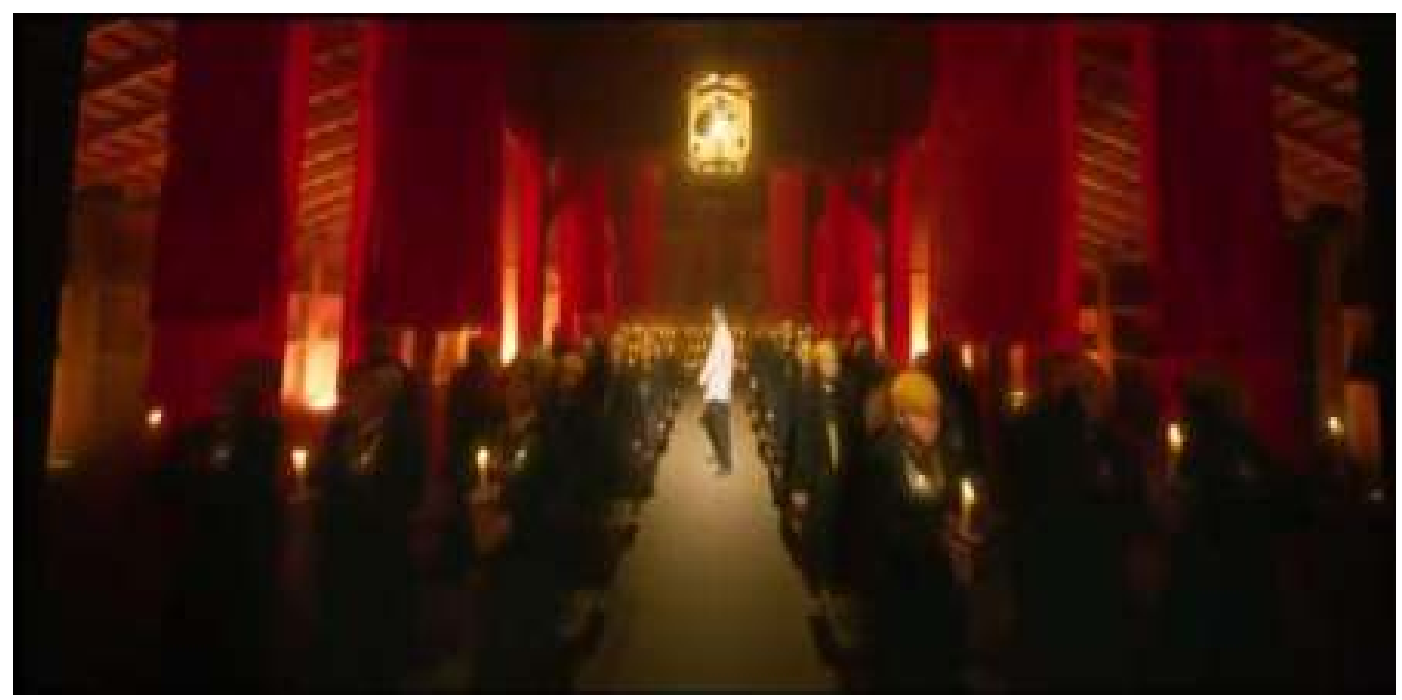

Gambar 6. Adegan Suga berada pada sebuah sekte (sumber: Capture video klip BTS “On”)

Satu-satunya dengan single segmen ialah Suga pada video klip BTS “On” yaitu berada dalam sekelompok sebuah sekte yang di tandai dengan kostum seragam bewarna gelap dan hanya Suga yang mengenakan baju bewarna putih cerah seolah menjadikannya pemimpin dalam sekte tersebut dan tergambar dalam kejeniusan Suga sebagai member yang paling banyak menciptakan lirik pada beberapa lagu mereka.

\section{KESIMPULAN}

Pada video klip BTS “On”, mereka selalu konsisten pada unsur-unsur pendukung struktur naratif yang mampu menggugah perasaan pengemarnya yang disebut ARMY. Kisah yang sengaja dibangun untuk mengundang persepsi simpati banyak anak muda hampir di seluruh Benua. Keberhasilan BTS pada music video diluar "On" telah meraih banyak penghargaan menjadi nilai fantastis bagi Big Hit Entertaiment. Dengan konsitennya Big Hit Entertaiment mengusung konsep cinematic video dalam video klip lagu nya membuat BTS ini memiliki nuansa yang berbeda dengan Boy Band lainnya.

Selain kreativitas konsep video klip BTS "On", kemampuan hakiki Big Hit Entertaiment dalam menciptakan persepsi baru bagi para penikmat musik mereka yang dianggap tak biasa oleh para penggemar K-Pop dan patut di apresiasi oleh para ARMY. Beberapa plot yang terdapat dalam video kilp lagu "On" dianggap oleh para Korean Wave memiliki makna kontroversi dan protes terhadap kebijakan tertentu dalam kehidupan nyata di Korea Selatan.

Unsur naratif yang mencangkup tokoh, alur cerita, dan lainnya dikonsep sedemikian rupa agar mampu membuat penonton melahirkan interpretasi makna terhadap visual yang dilihatnya. Melalui metode pendekatan secara deskriptif kualitatif serta teorit naratif yang digunakan menunjukkan bahwa dalam video klip lagu "On" terdapat makna yang tersembunyi di setiap adegan visual yang ditampilkan. Elemen unsur naratif yang terdapat dalam visual video klip lagu "On" terikat hubungan sebab akibat yang mampu membangun suatu peritiwa yang saling berhubungan. 


\section{DAFTAR PUSAKA}

[1] Armanto, RB. (2013). Skenario Teknik Penulisan Struktur Cerita Film. Jakarta: fakultas film dan televisi institut kesenian jakarta.

[2] Diari, Ni Made Krisna dan Mahyuni, Luh Putu. (2019). Strategi Sukses K-Pop Memasuki Pasar Musik Mainstream: Bighit Entertainment, BTS, dan 'Army'. Jurnal Manajemen Bisnis, 31-47.

[3] Hermansyah, Muhammad Ivan. (2019). Makna Simbolik Dalam Musik Video Klip Kendrick Lamar "Humble". Seminar Nasional Cendekiawan ke 5 Tahun 2019 Buku 2: "Sosial dan Humaniora".

[4] McCudden, Michelle L. (2011). Degrees Of Fandom:Authenticity \& Hierarchy In The Age Of Media Convergence. Artikel.Doctor of Philosophy ofCommunication Studies Faculty of the University of Kansas. Kansas: U.S.A.P.

[5] Murwonugroho, Wegig. 2015. Subjektivitas Dalam Iklan Murwonugroho, W., \& Pilliang, Y.A. (2015). Subjektivitas Dalam Iklan Ambient Media Miracle Aesthetic Clinic. Panggung, 25(2), 164-176. https://doi.org/10.26742/panggung.v25i2.6

[6] Moleong, Lexy J. (1993). Metode Penelitian Kualitatif. Bandung: Remaja Rosda Karya.

[7] Retno, Novi. (2018). Analisis Lagu Sebagai Penguat Unsur Naratif Pada Film Musikal "Rena Asih". Jurnal Tugas Akhir, Institut Seni Indonesia Yogyakarta.

[8] Pratista, Himawan. (2008). Memahami Film, Yogyakarta: Montase Press.

[9] Simbar, Frulyndese K. (2016). Fenomena Konsumsi Budaya Korea Pada Anak Muda Di Kota Manado. Jurnal Hoslistik, 1-20.

[10] Wahyuningsi, Suci, dan Budi, Rayudaswati. (2018). Visualisasi Makna Surealisme Pada Video Klip Up And Up (Perspektif Semiotika Charles Sanders Pierce)". Jurnal Al-Munzir. 